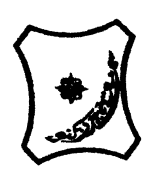

Bayero Journal of Pure and Applied Sciences, 12(1): 32 - 39

Received: September, 2018

Accepted: February, 2019

ISSN $2006-6996$

\title{
EMPIRICAL MODELS FOR ESTIMATION OF GLOBAL SOLAR RADIATION USING THE MONTHLY AVERAGE DAILY SUNSHINE HOURS DATA FOR MAKURDI, BENUE STATE.
}

\author{
*Sa'id, R. S., Akor, S. I. and Gana, U.M. \\ Department of Physics Bayero University, PMB 3011, Kano. Nigeria \\ *Correspondence Author: rssaidu.phy@buk.edu.ng
}

\begin{abstract}
This paper proposes empirical correlation models for estimating global solar radiation using data of sunshine hours for the location of Makurdi in Benue State of Nigeria. The paper suggests extrapolation of the empirical models for other locations with similar climatic conditions. The proposed models are: Linear, Quadratic, Cubic, Exponential, Power and Logarithmic models. Each of the models is based on Angstrom-Prescott equations for estimating global solar radiation. Any of the models can ease the use of sophisticated equipments, which are expensive, delicate and sometimes develop faults during measurement. The results of the models show that the cubic model is the best with slightly higher coefficient of determination. The coefficient of determination of each of the models was found to be $0.952,0.965,0.967,0.965,0.948 \& 0.924$ respectively, while the absolute correlation was found to be unity. Errors evaluated include MBE, RMSE and MPE with minimal values. The percentage diffuse and direct solar radiations, clearness index and the diffuse fraction were also estimated using the models. The results of the estimations done using the proposed models indicate that there is an estimated average annual global solar radiation of $6056 \mathrm{MJm}^{-2}$, monthly value of $505 \mathrm{MJm}$ 2 and daily insolation of $16.82 \mathrm{MJm}^{-2}$ sufficient enough for maximum solar radiation exploitation.
\end{abstract}

Keywords: Solar Radiation, Empirical Models, Diffuse Radiation, Direct Radiation

\section{INTRODUCTION}

Much of the current energy resources being harnessed is the fossil fuel energy whose rate of depletion is on the rise, particularly in Nigeria. It is therefore imperative to harness the solar energy resources to help meet the ever increasing energy demand in our country. The widely used renewable energy sources are solar and wind energies.

Solar radiation which arrives at the earth surface for every year is 160 times the worlds proven fossil fuels reserves (Yoshida, et a/ 2013).Nigeria is blessed with abundant amount of sunshine with an estimated 3000 hours of annual sunshine (Burari and Sambo, 2001).

To estimate the global solar radiation for Markudi using the monthly average daily sunshine hours, several empirical correlation equations have been proposed for use in the course of this research work.

They are based on the models developed by Angstrom (1924) and modified by Prescott (1940). And the diffuse solar radiation was estimated using the equation proposed by Page (1964). These equations have been frequently used to estimate the global and diffuse solar radiation in various places.

The results of the proposed models show a great deal of correlation with the measured data obtained from NIMET (Nigeria Meteorological Agency) Air Force Base, Markudi. Statistical tests carried out on each of the models revealed minimal errors and high magnitude of coefficient of determination, $\mathrm{R}^{2}$.

\section{METHODOLOGY:}

The monthly mean daily extraterrestrial radiation, $\mathrm{H}_{0}$ was computed from equation (1) and recorded as $\mathrm{H}_{0}$ in $\mathrm{MJm}^{-2}$ day $^{-1}$.

$$
\mathrm{H}_{\mathrm{o}}=\frac{24}{\pi} \cdot 3600 . \mathrm{G}_{\mathrm{sc}} \cdot\left(1+0.033 \cos \frac{360 \mathrm{~N}}{365}\right)\left[\cos 6 \cdot \cos \delta \cdot \sin \omega_{s}+\frac{\pi \omega_{s}}{180} \sin \phi \cdot \sin \delta\right] \text {. }
$$

where $\mathrm{G}_{\mathrm{sc}}$ is the solar constant $\left(\mathrm{G}_{\mathrm{sc}}=1367 \mathrm{~W} / \mathrm{m}^{2}\right)$

Sunrise and sunset hour angle is given by Fayadh and Ghazi (1983) as: 
BAJOPAS Volume 12 Number 1, June, 2019

$$
\text { where }
$$

$$
\mathrm{w}_{\mathrm{s}}=\operatorname{Cos}^{-1}(-\operatorname{Tan} \phi \cdot \tan \bar{\delta})
$$

$\emptyset$ = latitude $=7.68^{\circ} \mathrm{N}$ and $\delta$ is declination angle

The value of the declination can be found from the equation of Cooper (1969) as:

$$
\text { Declination angle } \delta=23.45 \sin \left[360\left(\frac{N+284}{365}\right)\right]
$$

where $\mathrm{N}$ is the number of days of the year starting from first of January.

The day-length (s) is given by: (Iqbal, 1983)

$$
\mathrm{s}=\frac{2}{15^{-1} w_{s}}
$$

Analysis on each of the models:

The Angstrom-Prescott models have constants evaluated with the aid of Microsoft Excel Programme. The models are given by the following relations:

$$
\begin{aligned}
& \frac{H_{m}}{H_{o}}=a+b\left(\frac{m}{s}\right) \text {.........(Linear Models) } \\
& \frac{\mathbf{H m}}{\mathbf{H o}}=a+b\left(\frac{M}{s}\right)+c\left(\frac{m}{\sigma}\right)^{2} \text {......(Quadratic Model) } \\
& \frac{I l_{m a}}{H_{o}}=a+b\left(\frac{M}{s}\right)+c\left(\frac{m}{s}\right)^{2}+d\left(\frac{m}{s}\right)^{2} . \\
& \frac{H_{m}}{H_{o}}-a v^{b}\left(\frac{m}{s}\right) \\
& \frac{H_{m}}{H_{o}}=a[m / s]^{b} \\
& \frac{H_{m}}{H_{o}}=a+b\left[\ln \left[\left(m_{/ s}\right)\right]\right] . \\
& \text {.Exponential Model } \\
& \text { (Cubic Model) (7) }
\end{aligned}
$$

(TijjaniandMusa, 2011).

where $a, b$ and $c$ are arbitrary constants. The parameter $s$ is the day length, $H_{m}$ is the observed horizontal terrestrial solar radiation while $\mathrm{H}_{0}$ is the extra-terrestrial solar radiation on a horizontal surface. The total number of meteorological variables under study is $n$. The measured data obtained from NIMET $\left(\mathrm{H}_{m} \& n\right)$ and the calculated parameters $\left(\mathrm{H}_{0} \& \mathrm{~s}\right)$ were inputted into the above equations (7) to (12) and for each model analysis was carried out to evaluate the constants with the aid of Microsoft Excel Program. The chart of the analysis on each model is shown in the proceeding page.

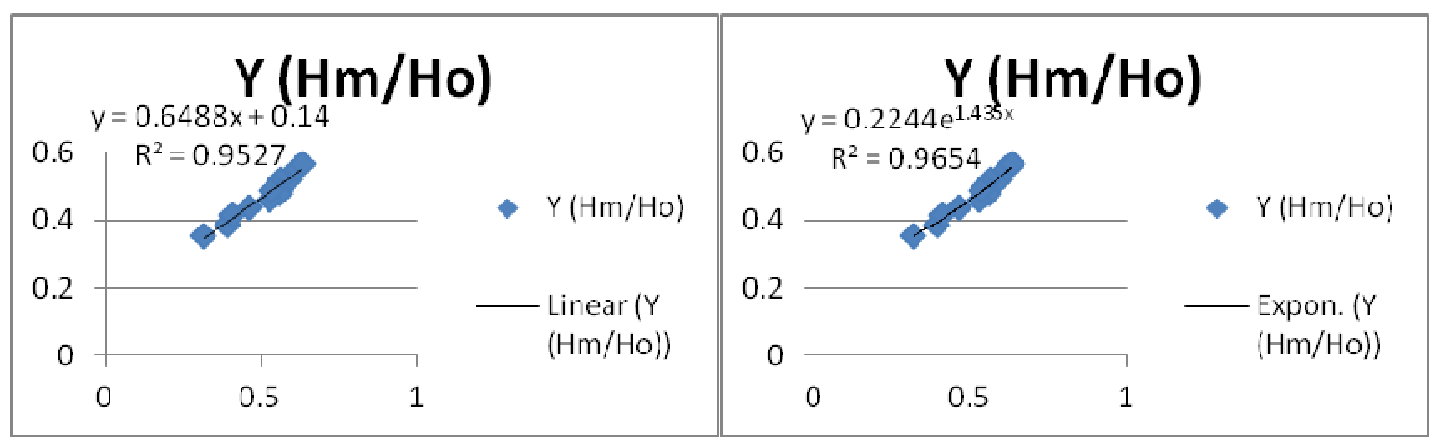

Figure1: Correlation of the Linear Model

Figure 2: Correlation of the Exponential Model 


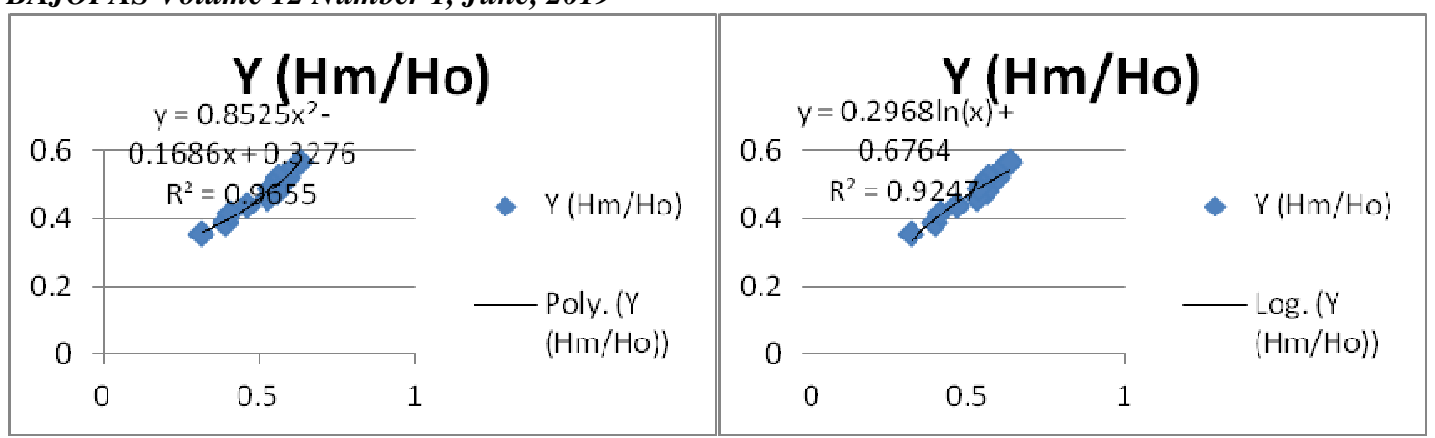

Figure 3: Correlation of the Quadratic Model Figure4: Correlation of the Logarithmic Model

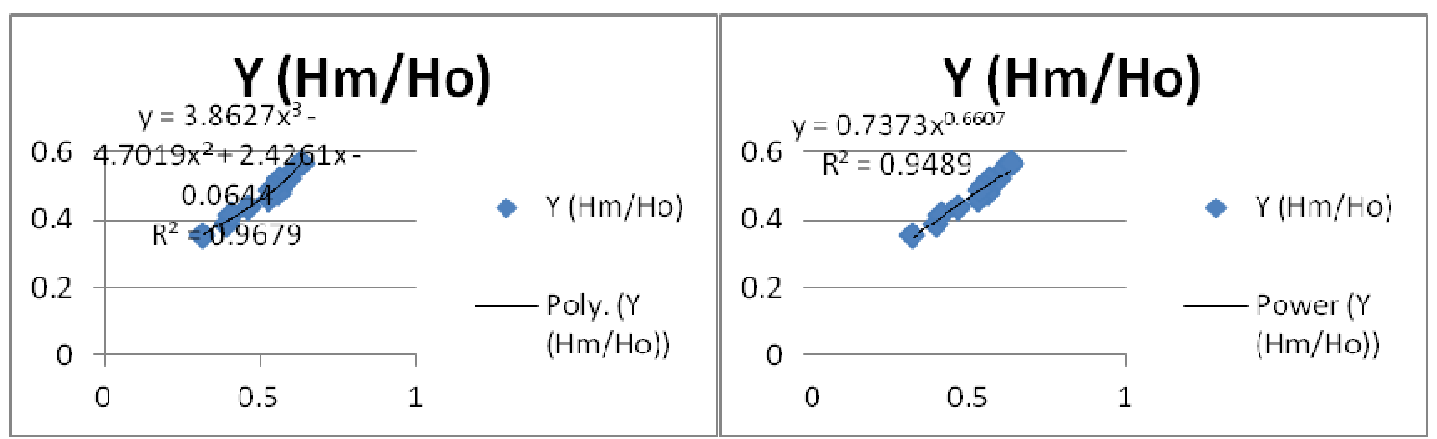

Figure 5: Correlation of the Cubic Model

Figure 6: Correlation of the Power Model

\section{RESULTS OF ANALYSIS}

The evaluation of the constants results into the formulation of the proposed models that can be used to estimate the global solar radiation of the research location Makurdi and other areas with similar climatic conditions. They are given by the following relations:

$$
\begin{aligned}
& \frac{H_{c a l}}{H_{n}}=0.140+0.648\left(\frac{m}{s}\right) \\
& \frac{H_{\mathrm{cal} \mathrm{a}_{\mathrm{a}}}}{\mathrm{Ha}}=0.327-0.168\left(\frac{m}{\mathrm{~g}}\right)+0.352\left(\frac{\mathrm{m}}{\mathrm{s}}\right)^{2} \\
& \frac{H_{c c l}}{H_{\mathrm{n}}}=-0.064+2426\left(\frac{m}{G}\right)-4.701\left(\frac{n}{G}\right)^{2}+3.862\left(\frac{M}{G}\right)^{3} \\
& \frac{H_{\text {cal. }}}{H_{s}}=0.224 \mathrm{e}^{1.435(\mathrm{f} / \mathrm{s})} \\
& \frac{H_{c c l . s}}{H_{s}}=0.737\left(\frac{m}{s}\right)^{0.660} \\
& \frac{H_{c n l}}{H_{s}}=0.0576+0.296 \ln (/ / s)
\end{aligned}
$$

The diffuse solar radiation was estimated using the equation proposed by Page (1964) given by:

$$
\frac{H_{d}}{H_{m}}=1.0-1.13\left(\frac{H_{m}}{H_{o}}\right)
$$

\section{RESULTS AND DISCUSSION}

The results are presented in Table1 as well as Figures 1-16. This is followed by the discussion of the results.

Table 1: Statistical analysis of data

\begin{tabular}{lllllll}
\hline & Linear & Quadratic & Cubic & Exponential & Power & Logarithmic \\
\hline $\mathrm{R}^{2}$ & 0.0952 & 0.965 & 0.967 & 0.965 & 0.948 & 0.924 \\
MBE & -0.050 & -0.0167 & 0.014 & -0.036 & -0.0011 & 0.0150 \\
RMSE & 0.431 & 0.058 & 0.405 & 0.434 & 0.0037 & 0.0521 \\
MPE & $0.28 \%$ & $0.07 \%$ & $-0.12 \%$ & $0.19 \%$ & $-0.002 \%$ & $-0.083 \%$ \\
& & & & & &
\end{tabular}


BAJOPAS Volume 12 Number 1, June, 2019

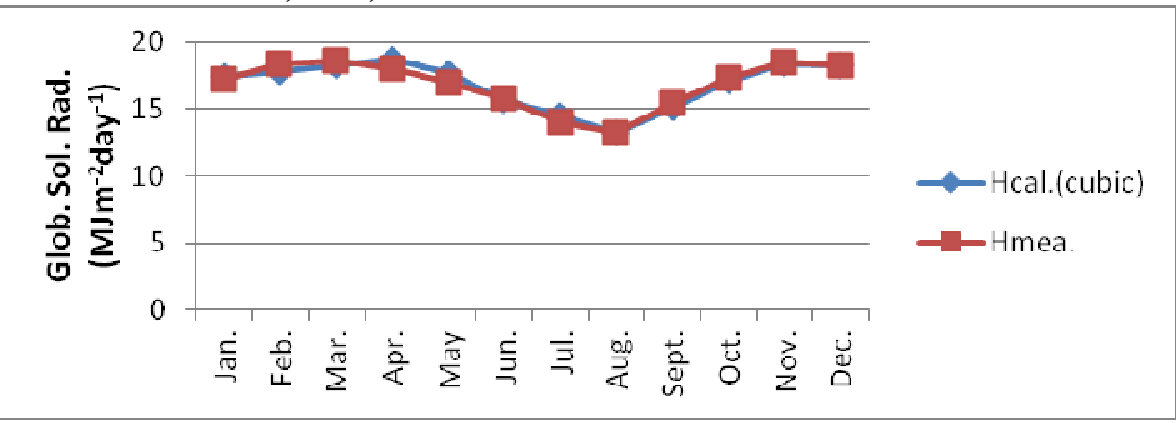

Figure7. Comparison of monthly variation of the measured and calculated Global Solar Radiation (Cubic Model)

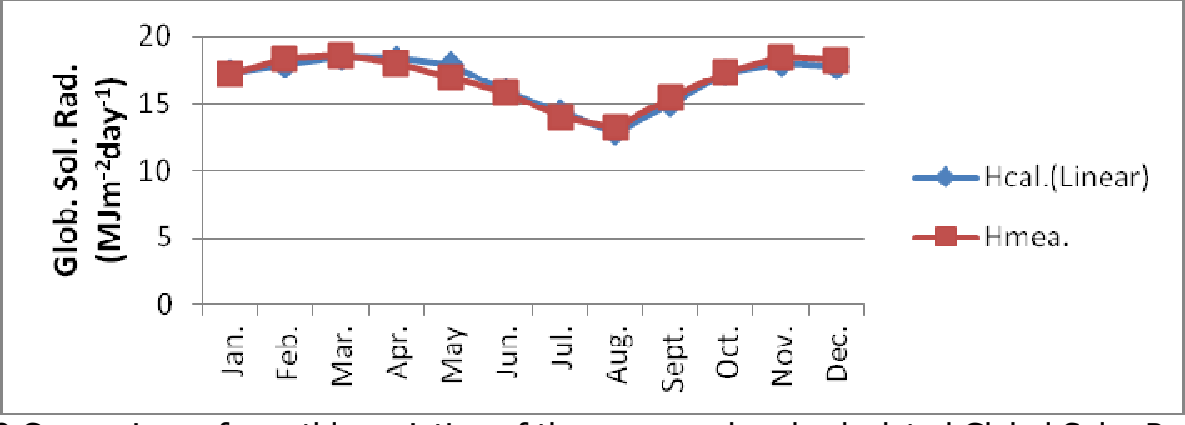

Figure8.Comparison of monthly variation of the measured and calculated Global Solar Radiation (Linear Model)

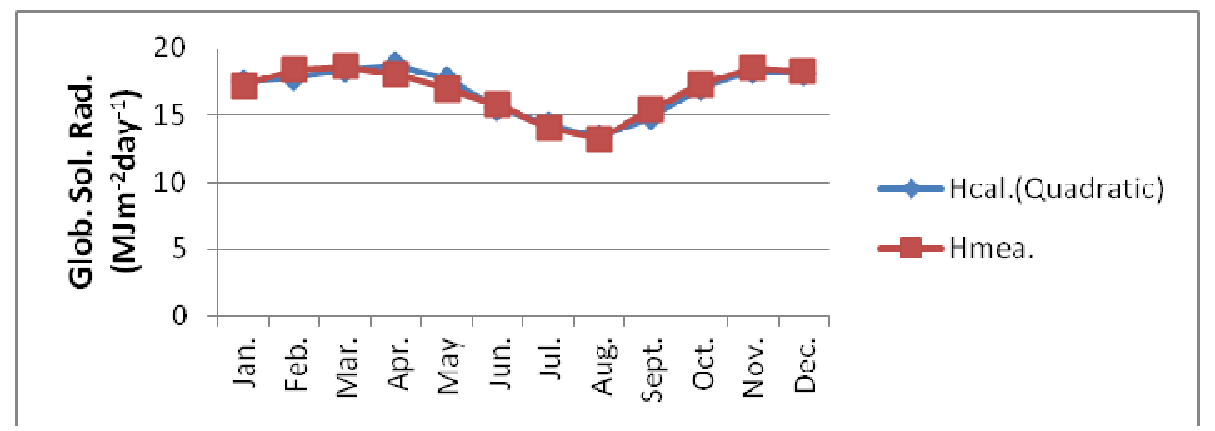

Figure9.Comparison of monthly variation of the measured and calculated Global Solar Radiation (Quadratic Model)

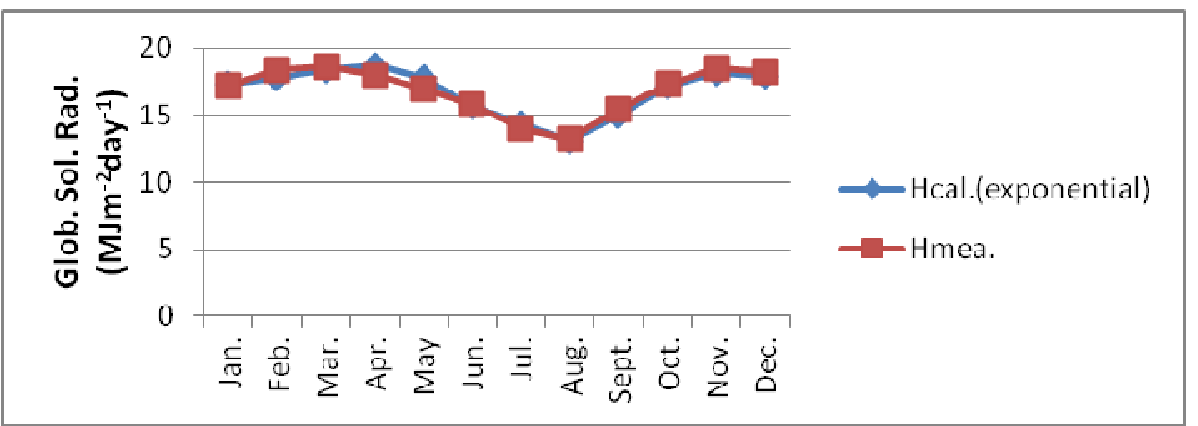

Figure10. Comparison of monthly variation of the measured and calculated Global Solar Radiation (Exponential Model) 
BAJOPAS Volume 12 Number 1, June, 2019

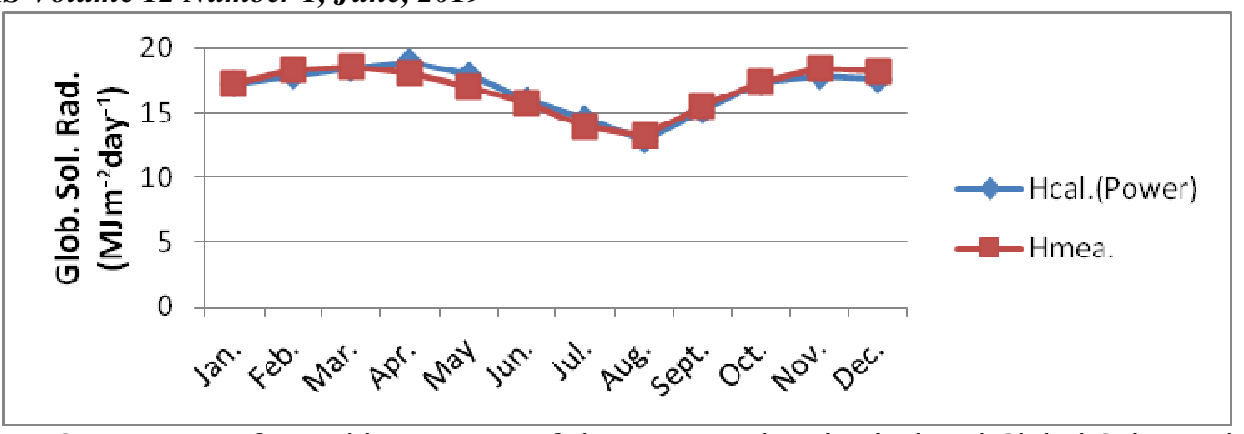

Figure11.Comparison of monthly variation of the measured and calculated Global Solar Radiation (Power Model)

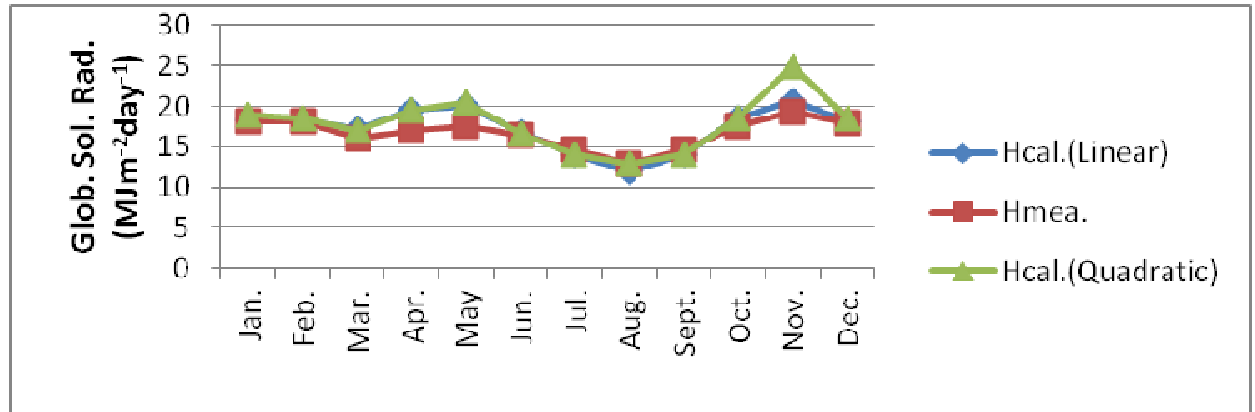

Figure12. Comparison of monthly variation of the measured Global Solar Radiation with the linear and quadratic models

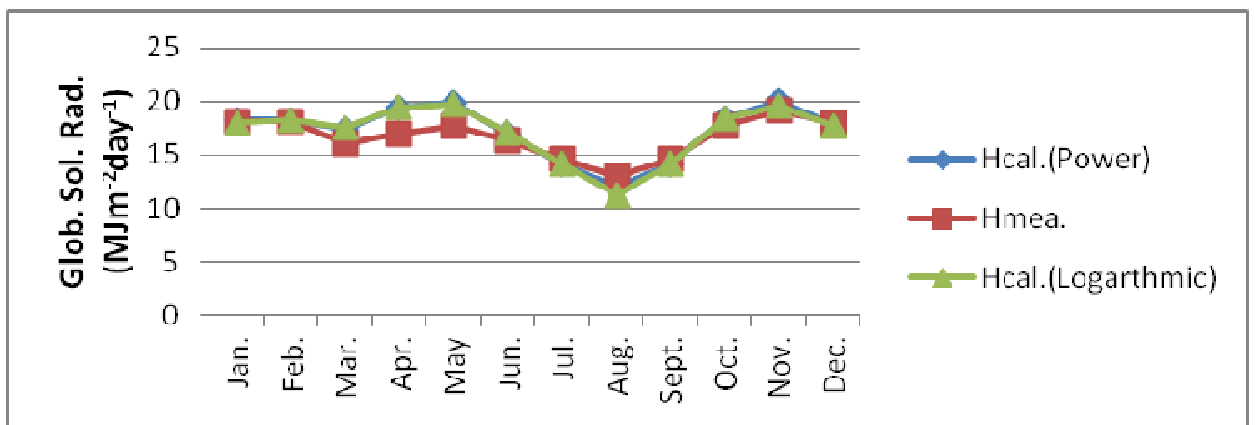

Figure13. Comparison of monthly variation of the measured Global Solar Radiation with the power and Logarithimic models

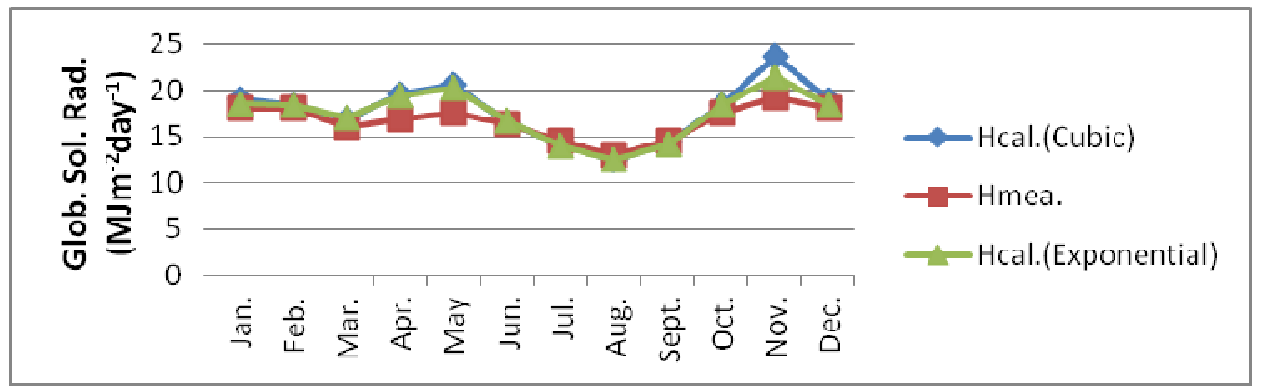

Figure14.Comparison of monthly variation of the measured Global Solar Radiation with the Cubic and Exponential models 
BAJOPAS Volume 12 Number 1, June, 2019

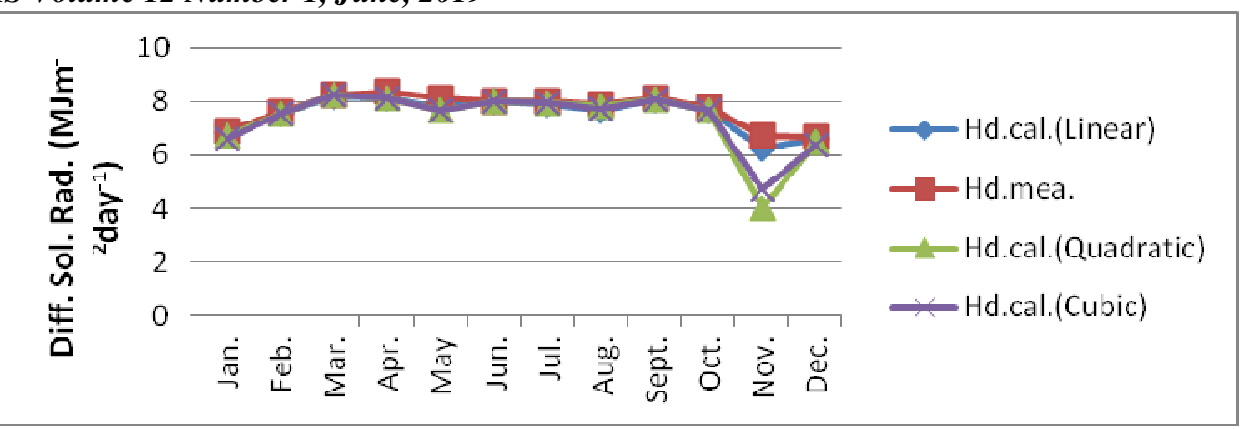

Figure15.Comparison of monthly variation of the measured Global Solar Radiation with the calculated linear, cubic and quadratic models

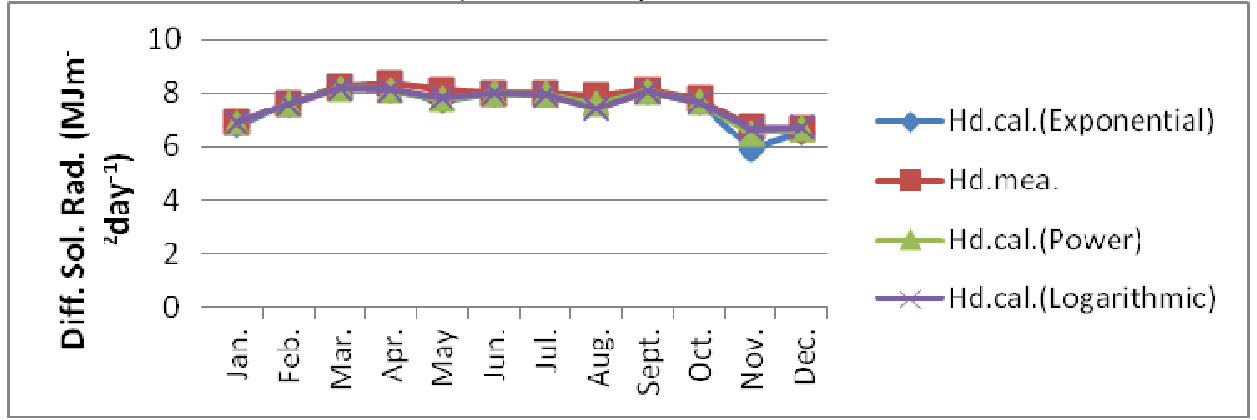

Figure16. Comparison of monthly variation of the measured Global Solar Radiation with the calculated exponential, logarithimic and power models

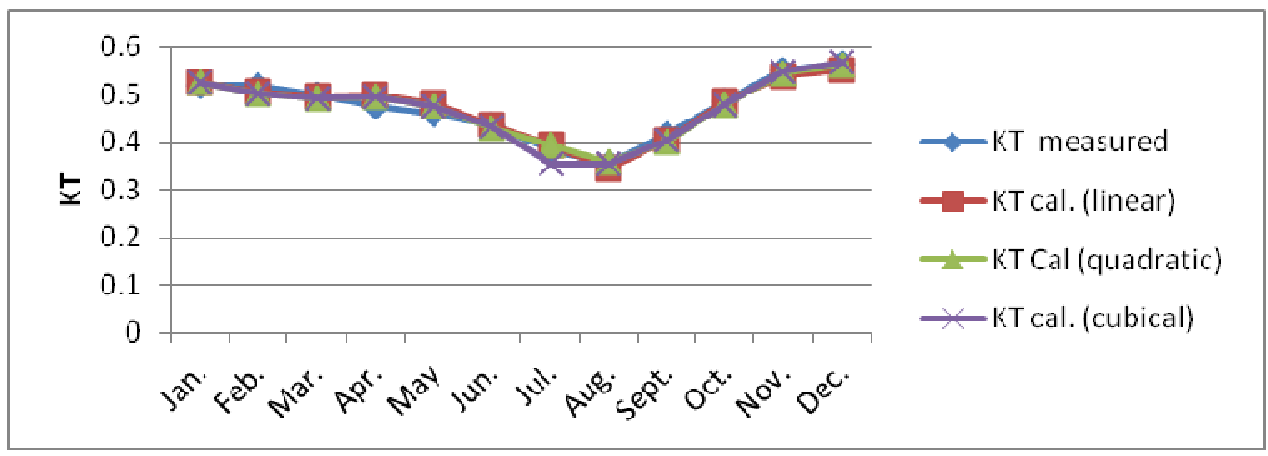

Figure17. Comparison of monthly variation of the measured clearness index with the calculated linear, cubic and quadratic models

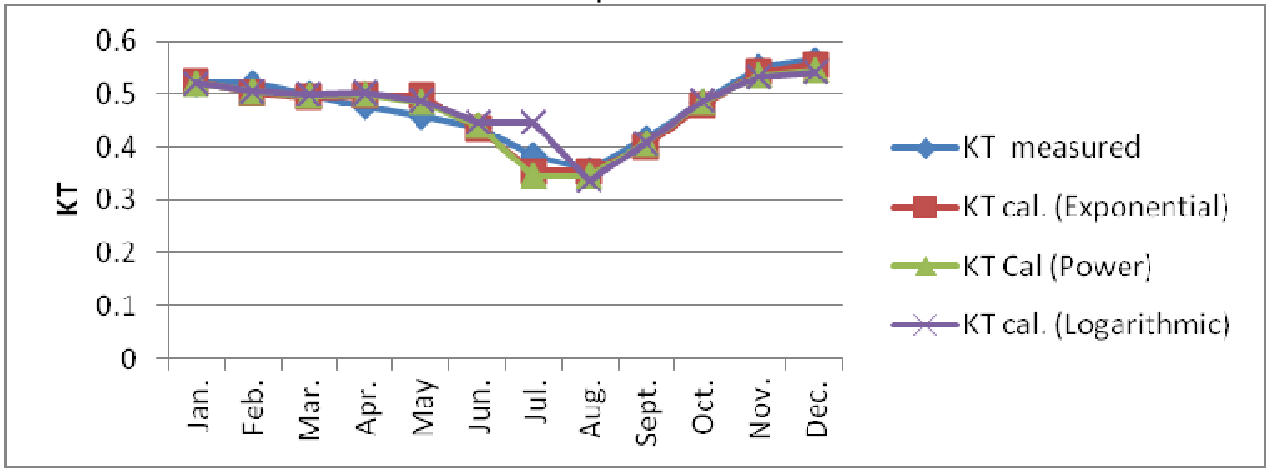

Figure18. Comparison of monthly variation of the measured clearness index with the calculated exponential, power and logarithimic models 
BAJOPAS Volume 12 Number 1, June, 2019

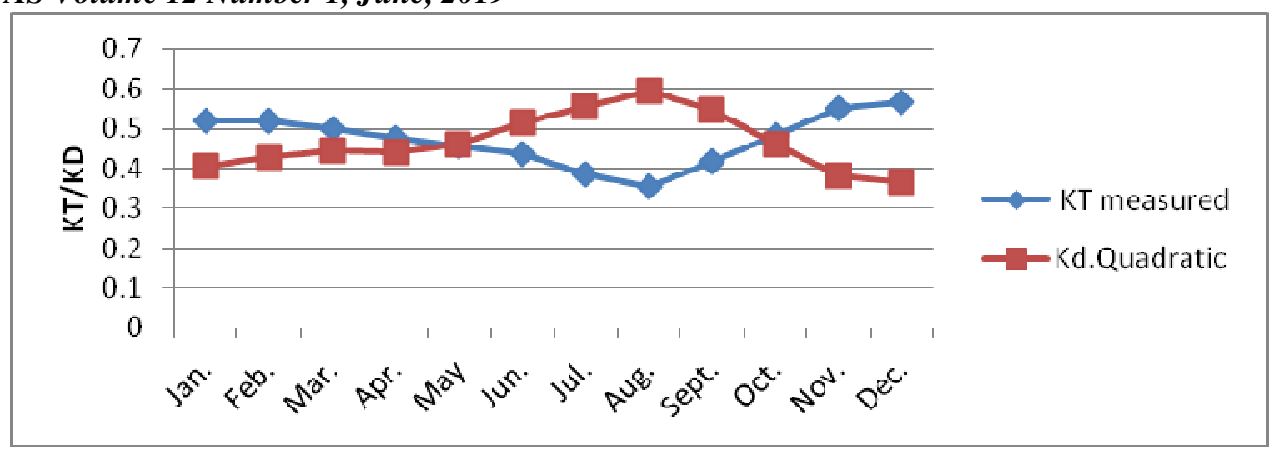

Figure 19. Comparison of monthly variation of the measured clearness index with the calculated index from the quadratic model

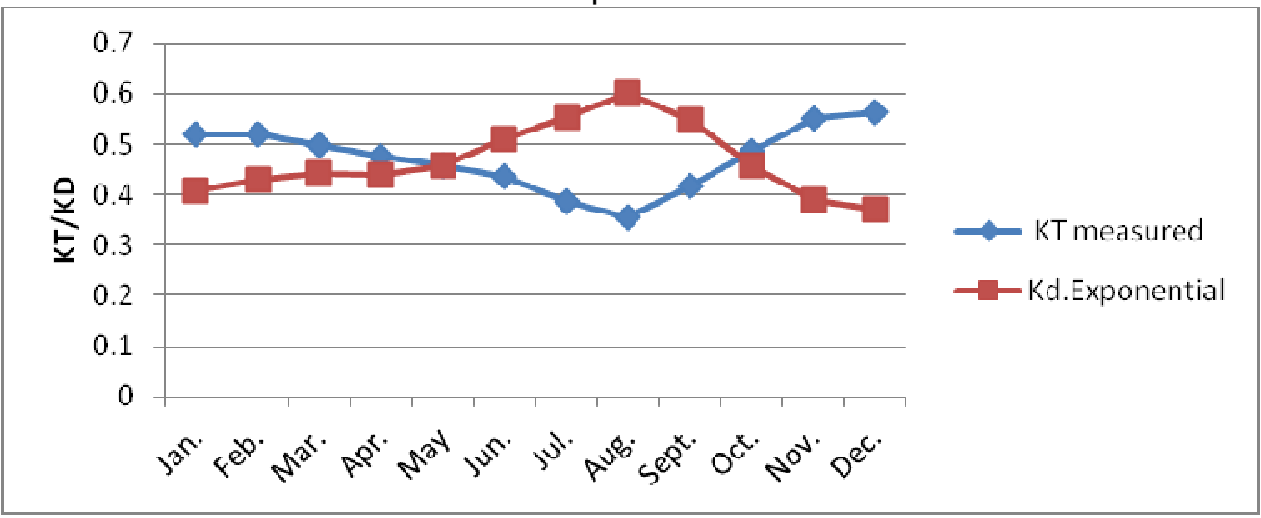

Figure20.Comparison of monthly variation of the measured clearness index with the calculated index from the exponential model

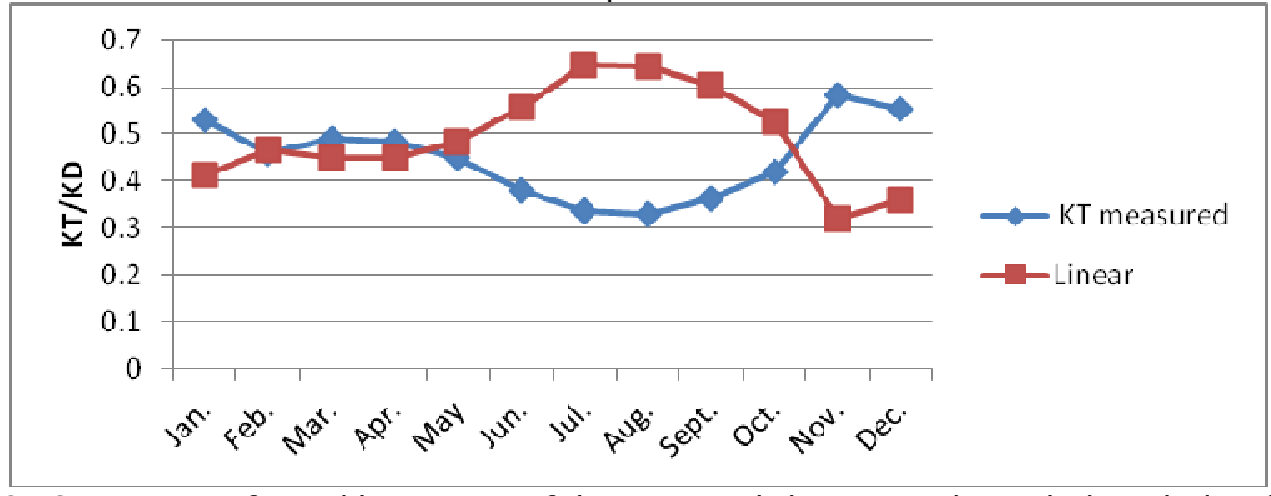

Figure21.Comparison of monthly variation of the measured clearness index with the calculated index from the linear models

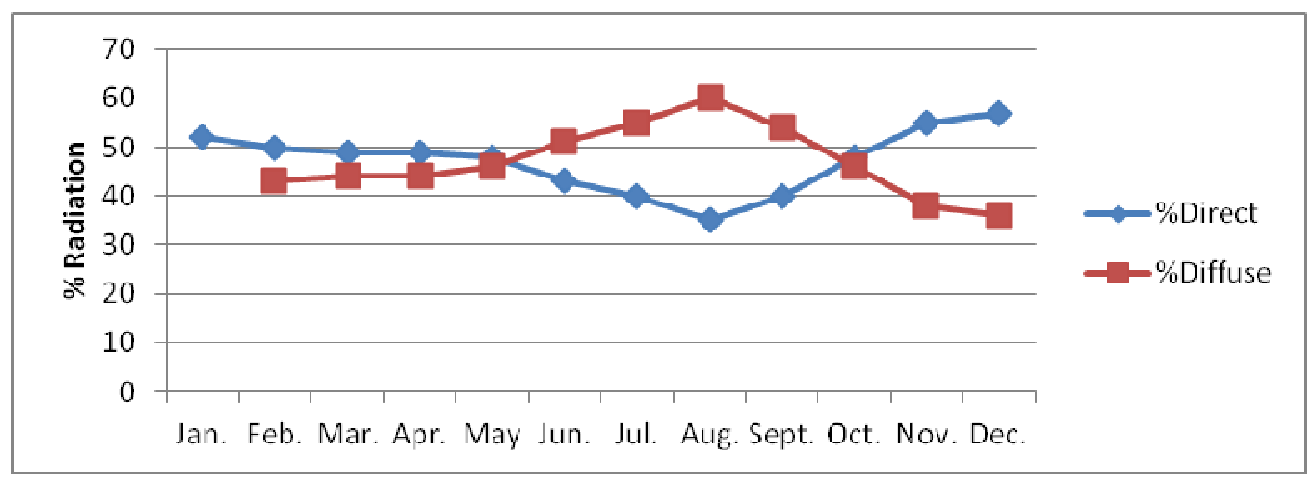

Figure22.Comparison of monthly variation of the percentage diffuse radiation to the percentage of direct radiation 
BAJOPAS Volume 12 Number 1, June, 2019

\section{DISCUSSION}

Figures 7-11 show the comparison of Measured and Calculated Global Solar Radiation for each of the Models. Figures 12-14 compare the measured and calculated global solar radiation for the location for each of two models. Figures 15-18 compare the calculated clearness index of the models with the measured values, while Figures 19-21 compare the measured clearness index with that calculated by each of the individual models. Figure 22 compares the percentage of diffuse solar radiation with the direct solar radiation.

The results reveal the correlation between the calculated and measured data. Low solar Further observation shows that when the percentage of the diffuse radiation is high, the percentage of the direct radiation is low. This is similar to the variation of the diffuse fraction and clearness index. Variations are also due to the cloudy nature of the atmosphere and the presence of particles in the atmosphere, which strongly attenuate solar radiation during the months of November, December and January.

\section{CONCLUSION}

The results obtained using the proposed models are in much correlation with the measured data

\section{REFERENCES}

Angstrom, A.J (1924). "Solar and Terrestrial Radiation". Q.J Rong Met. Soc. 50: pp $121-126$

Burari, W.F., and Sambo, S.A. (2001)."Model for the Prediction of Global Solar Radiation for Bauchi Using Meteorological data". Renewable Energy. 9(1\&2): pp 1233

Cooper, P.I. (1969). "The Absorption of Solar Radiation in Solar Stills".Solar Energy. 12 (3):pp 313-317

Fayadh, M.A and Ghazi A. (1983), Estimation of global solar radiation on horizontal surface over Haditha, Samara and Beji, Iraq. Pacific Journal of Sci. and Tech. 11: pp 73-82.

Igbal, M. (1983), An Introduction to Solar Radiation.Academy Press, New York.Pp 89.

Page, J.K., (1964). "Estimation of the Monthly Mean Values of daily Short Wave insolation is indicated by trough seen in the graphs due to the overcast experienced between May and October in the raining season.

The gaps between the lines of graph depict the disparity between estimated and measured data. Obviously due to error in model/instrument used in measurement. The gap between May and October depicts heavy presence of cloud cover with high diffusion fraction in rainy season. Where the lines cross in the graphs of solar radiation between October and November signify change into dry season and is observed by a clearness index $\mathrm{K}_{\mathrm{T}}$ thatis high.

by NIMET. Hence, the models are recommended for use to estimate the global solar radiation in Makurdi, Benue State and other regions with similar climatic conditions. The results of the estimations done using the proposed models show that there is an estimated average annual global solar radiation of $6056 \mathrm{MJm}^{-2}$, monthly value of $505 \mathrm{MJm}^{-2}$ and daily insolation of $16.82 \mathrm{MJm}^{-2}$ sufficient enough for maximum solar radiation exploitation.

Radiation on Vertical and Inclined Surfaces from Sunshine Records for Proceeding UN Conference on New Sources of Energy". Rome, Italy, United Nations. Pp.21-31.

Prescott, J.A (1940). Evaporation from water surface in relation to solar radiation. Trans R. Soc. S. Austr. 64. Pp 114-118

Tijjani, B.I and Musa A.O. (2011). Estimation of Global and Diffuse Solar Radiation from monthly average daily sunshine hours data in Katsina, Nigeria.Bayero Journal of Physics and Mathematics Vol. 4 N. 1 Dec. 2011. Pp. 12-16.

Yoshida, S., Ueno, S., Kataoka, N., Takakura, H., and Minemoto, T. (2013). "Estimation of Global titled Irradiance and output energy using meteorological data and performance of photovoltaic modules" Solar Energy 93: pp. 90 - 9. 